\title{
Michel Serres, historiador de las ciencias*
}

\author{
Bernadette Bensaude-Vincent ${ }^{\star \star}$ \\ Traducción del francés al español de Luis Alfonso Paláu-Castaño \\ Universidad Nacional de Colombia, Medellín, Colombia \\ lapalau@gmail.com
}

Entre todos los títulos que se le atribuyen a Michel Serres -filósofo, escritor, académico...-, rara vez se recuerda el de historiador. Sin embargo, es el que le conviene por profesión desde que el departamento de historia de la Universidad París le confió en 1970 una cátedra de historia de las ciencias. Este aspecto de su carrera es invariablemente ocultado aunque él no tenga nada de episódico, puesto que Serres enseñó historia de las ciencias durante cerca de treinta años. Formó una generación entera de estudiantes en la Sorbona y dirigió una obra colectiva Elementos de historia de las ciencias, que sirvió de manual a gran cantidad de estudiantes durante una buena decena de años. Cuando se conoce el prestigio de la Sorbona y el renombre de la escuela francesa de historia, se puede pensar que acogiendo a Serres los historiadores reconocían en él a uno de los suyos. Este sentimiento de pertenencia parece que Serres no lo hubiera experimentado nunca. La sola identidad que reivindica verdaderamente es la de filósofo de lengua francesa, incluso si cuenta con múltiples títulos como matemático, hijo de campesino o ex marino. Las noticias biográficas, espejo de este autorretrato, reproducen a gusto estas fórmulas cliché sin hacer mención de ninguna actividad de historiador.

A Serres no le gusta que se lo sitúe en una corriente, una época, una tradición ${ }^{1}$, él no es alumno de nadie. Nunca ha pretendido fundar un movimiento, ni una escuela, nunca se ha afiliado en un campo contra otro. Serres aborrece la dimensión agonística de la vida intelectual universitaria, y despliega su pensamiento en un mundo donde no hay verdaderamente adversarios pero tampoco

Cómo citar: Bensaude-Vincent, B. (2019). Michel Serres, historiador de las ciencias. Ciencias Sociales y Educación, 8(16), 175-188. DOI: https://doi.org/10.22395/csye.v8n16a12

Traducción realizada por Luis Alfonso Paláu-Castaño. Agradecemos a la editorial L'Herne permitir el acceso del libro en francés para su versión, en partes, en español. Se conserva la versión editorial en francés.

Recibido: 10 de agosto de 2019.

Aprobado: 20 de septiembre de 2019.

** Profesora de la Universidad París Oeste, y miembro del Instituto universitario de Francia; adelanta investigaciones en historia y filosofía de las ciencias y de las nuevas tecnologías, y se interesa igualmente en las relaciones entre ciencia y público. Es la autora, entre otros, de Faut-il avoir peur de la chimie? (Seuil, 2005); Se libérer de la matière? Fantasmes autour des nouvelles technologies (INRA, 2004); Les vertiges de la technoscience (Découverte, 2009).

1 Ilustra su resistencia a las tentativas de "posicionamiento" de Bruno Latour en Aclaraciones (2010, pp 6-8). Nota del traductor. 
aliados. Cultivando un estilo muy personal ha rechazado cuidadosamente toda etiqueta. Y sin embargo yo reivindico para él — sin duda a pesar de él一 el título de historiador de las ciencias ${ }^{2}$ "de lengua francesa". Voy a tratar aquí de presentar a Serres en el contexto de esta disciplina en Francia como el heredero de una tradición. La intención no es dar al César lo que es del César, y mucho menos escrutar filiaciones o influencias. Se trata de mostrar en qué esta obra que se quiere "desprendida", moviliza una larga tradición de historia filosófica de las ciencias que Serres ha trasmitido a sus estudiantes y lectores, torciéndola al hilo de los cursos y los libros hacia una antropología de las ciencias.

\section{La tradición francesa}

Comencemos con un breve recuerdo sobre lo que se puede designar como una tradición francesa de filosofía de las ciencias. Es aquí señalada por su importancia. La comunidad filosófica francesa está a la escucha de las ciencias. A comienzos del siglo XX es el rasgo dominante en el cuadro de la filosofía francesa: Émile Boutroux (1911) en el Cuarto Congreso Internacional de Filosofía en Bolonia o Bergson (1915) en su reporte sobre el estado de la filosofía francesa (P. 31).

La tradición francesa se distingue, en segundo lugar, de la filosofía analítica que se desarrolla en los años treinta, primero en Viena, luego en Inglaterra y los Estados Unidos por un vínculo estrecho con la historia de las ciencias. La reflexión sobre las ciencias se ancla en el estudio del pasado, en particular en las matemáticas y la física antiguas, en la mecánica de la época clásica y la termodinámica. Algunos como Émile Meyerson declaran entregarse a un análisis a posteriori de los productos del pensamiento; otros como Léon Brunschvicg, presentan la historia como el laboratorio de la filosofía. El paso por la historia está íntimamente asociado a la noción francesa de epistemología, término que comienza a ser utilizado por diversos autores hacia 1900.

Además, esta tradición epistemológica que estudia el intelecto humano a través de la historia de las ciencias, se desarrolló en paralelo con el estudio de las estructuras mentales promovido por Lucien Lévy-Bruhl en los años treinta. Con los debates sobre las mentalidades, sobre la unidad o la pluralidad de la razón humana, tomó un giro más bien cultural en el mismo momento en que el Círculo de Viena tomaba un giro lingüístico y lógico, y se fijaba como programa la unidad de las ciencias. El doble enlace entre historia y filosofía de las ciencias por una parte y ciencia y civilización por la otra toma su fuente en la obra de Auguste Comte (1975), la que Michel Serres meditó largamente y comentó cuando participó en la reedición del Curso de filosofía positiva. Fue

El traductor de este artículo hace otro tanto pues fue su alumno en Historia de la termodinámica en el DEA. en Historia de las ciencias de la Sorbona en el año escolar 1976-1977. Nota del traductor. 
para un discípulo de Comte que se creó en 1892 la primera cátedra de historia de las ciencias en el Collège de France. Y a comienzos del siglo XX los filósofos de las matemáticas como Édouard Le Roy o Abel Rey se filiaron gustosos bajo el estandarte del "nuevo positivismo" (Brenner, 2003). Si el positivismo fue motor de la investigación francesa en historia de las ciencias, esto tiene que ver sin duda con la opinión de su fundador Auguste Comte, que consideraba que solo se puede conocer una ciencia a través de su historia. Pero es también más durable por que el positivismo funciona como una referencia constante, sea como un modelo para superar, sea lo más frecuente como la mira de despiadadas críticas.

La herencia positivista es reivindicada por Georges Canguilhem (1992a) con ocasión del centenario de la muerte de Auguste Comte en 1958, para caracterizar un "estilo francés de historia de las ciencias". Este estilo nacional contrasta con la historia erudita donde la recolección del pasado es un fin en sí mismo. El impulso positivista imprime una orientación muy filosófica, muy alejada de la historia profesional que se desarrolla hacia fines del siglo XIX. Comte nunca se entrega a pesquisas minuciosas sobre el pasado de las ciencias a las que el Curso le pasa revista. Practica más bien "el vistazo" y presenta a grandes rasgos las épocas conforme a su ley de los tres estados. Mientras que los sucesores de Comte detentadores de la primera cátedra de historia de las ciencias - Charles Laffitte, luego Grégoire Wyrouboff — viran hacia el positivismo religioso, y hacen catecismo más que historia de las ciencias; otros sabios filósofos historiadores como Paul Tannery, Henri Poincaré, Pierre Duhem, Gaston Milhaud, Édouard Le Roy, Émile Meyerson toman sus distancias. Practican una historia intelectual atenta a la evolución de las ideas, de los conceptos y teorías, indiferente al medio social y político donde nacen esas ideas. Está al servicio de una teoría del conocimiento. El vínculo fuerte entre la filosofía y la historia de las ciencias no implica necesariamente que se deba sancionar el pasado en nombre del presente. Esta actitud promovida por Bachelard, es incluso severamente juzgada por un filósofo historiador como Émile Meyerson y sus discípulos, Hélène Metzger y Alexandre Koyré. El papel de sanción concedido al presente de la ciencia instaura de hecho una especie de bifurcación en la tradición francesa entre dos escuelas rivales.

En los años sesenta cuando comienza la carrera de Serres, la ruptura se manifiesta en el espacio parisino. Por un lado, en el edificio de Nevers donde se ha instalado una antena de la Escuela de Altos Estudios en Ciencias Sociales, bautizada Centro Alexandre Koyré, un grupo practica la historia erudita de las ciencias del pasado a través de los textos originales; por el otro lado, Calle du Four, bajo el cayado de Bachelard, luego de Georges Canguilhem en el Instituto de Historia de las Ciencias y de las Técnicas, integrado a la Sorbona, se prefiere 
la historia epistemológica, una historia juzgada, sancionada, que desprecia la historia erudita juzgada puramente descriptiva ${ }^{3}$.

A pesar de las sordas tensiones entre las dos escuelas, las dos desarrollan un enfoque intelectual que privilegia conceptos y teorías. La historia de las ciencias de la francesa contribuyó esencialmente a nutrir una filosofía del concepto. En un homenaje rendido a Canguilhem en 1985, Michel Foucault evoca una grieta en el seno de la filosofía francesa entre la filosofía del sujeto y la "filosofía del saber, de la racionalidad y del concepto" que procede de Comte, prosigue con Poincaré, Couturat, Cavaillès, etc. Foucault se compromete explícitamente con esta tradición de filosofía del concepto. Pero, ¿qué ha pasado con Serres?

\section{Dudas sobre la epistemología}

Aunque disponga de una cátedra en historia, Serres no entra verdaderamente en la comunidad de los historiadores. Expresa ciertamente su gratitud al comienzo de Roma, pero se percibe como un exiliado, refugiado político en esa comunidad: "Con el presente libro y, si la vida no me es demasiado dura, con algunos otros que lo seguirán, expreso mi agradecimiento a la comunidad de los historiadores que me acogió, hace ya trece años, cuando el grupo de presión entonces en el poder me expulsó de mi viejo paraíso: la filosofía. Lo que me hizo la vida dura" (Serres, 1988, p.2). Sus cursos de historia de las ciencias en la Sorbona atraían una muchedumbre inmensa que era preciso acomodar en un anfiteatro. Pero entre los escuchas que llenaban "el anfiteatro de las vacas" el sábado por la mañana, los estudiantes de historia se contaban en los dedos de las manos. Como no buscó aproximarse a sus colegas historiadores en la Sorbona, Serres tampoco le prestó atención a los debates y trabajos que se llevaban a cabo en los departamentos de historia de las ciencias de las universidades estadounidenses donde tuvo múltiples estadías.

¿Por qué el diálogo nunca se estableció con los historiadores? La historia de las ciencias atraía ciertamente a muy pocos historiadores, sobre todo porque Serres ya había escogido su vía. Se había comprometido resueltamente al comienzo de su carrera en esa tradición de "filosofía del saber, de la racionalidad y del concepto" que evoca Foucault. Escoge el concepto más bien que el sujeto, el sistema de Leibniz más bien que el sujeto cartesiano y se burla gustoso de los fenomenólogos. Navegando en Leibniz se ejercita en una filosofía de la relación, abandonando las que piensan el ser.

En el primer Hermes o la comunicación, Serres busca inscribirse en un linaje post-bachelardiano. Presenta a Bachelard como el último de los simbolistas que cerró una época saturando el espacio de los símbolos, en la encrucijada entre

3 Ver Georges Canguilhem. "El objeto de la historia de las ciencias". in Op. cit., pp. 3-11. 
ciencia y cultura. Al simbolismo le sucede la edad del formalismo al que Michel Serres declara pertenecer. Al mismo momento en que se esfuerza por depurar la noción de estructura cargada de escorias por la moda estructuralista, repatriándola a su terreno matemático de origen, Serres (año) enuncia su programa: "evidenciar el rigor estructural del amontonamiento cultural" (p. 29). En 1968 la generación estructuralista no ha roto aún sus lazos con la precedente: al escoger la historia y la filosofía de la medicina, Foucault le encaja el paso a Canguilhem, mientras que Serres avanza tras las huellas de Bachelard, cultivando la epistemología de las matemáticas y la física.

Desde el Hermes I, Serres plantea una duda sobre la tradición epistemológica que lo ha nutrido, dialogando con la obra de un filósofo de las matemáticas como Le Roy. ¿Cuál es la función del epistemólogo? ¿Cuál es la legitimidad de esta mirada exterior? El análisis reflexivo de un estado de crisis en un metalenguaje filosófico será próximamente interiorizado y vuelto a traducir en lengua científica. Entonces, ¿pra qué la epistemología? ¿Serán parásitos los epistemólogos? La duda de Serres procede de dos convicciones: la resolución de una crisis en matemáticas pasa necesariamente por el análisis reflexivo; y la ciencia es un proceso auto-normado, auto-regulado.

\section{Una historia imposible}

Después de haber dudado de la epistemología, Serres duda de la historia de las ciencias. Es en su propia práctica de la historia de las ciencias — no de lo alto de alguna atalaya filosófica, en picado-donde surge la duda. En 1977 Serres publica dos estudios de historia de las ciencias en forma de provocaciones blandiendo evidencias fundamentales.

El nacimiento de la física en el texto de Lucrecio. Ríos y turbulencias, este título manifiesta una intención polémica. Subvierte el esquema positivista clásico (que remitía los textos de la antigüedad a la categoría metafísica o precientífica), proclamando que se trata allí de un texto fundador de la física. En esta obra - una de las escasas que haya sido escrita en estilo argumentativo-, Serres se dedica a un análisis fino del De rerum natura de Lucrecio. Ese poema habitualmente leído como un gran texto poético, literario y filosófico es considerado aquí como un tratado científico. Serres discute pues toda demarcación entre los géneros: ciencia, metafísica, literatura. Más allá de la crítica de la ley de los tres estados, es el culto de las revoluciones científicas y de la ruptura epistemológica el que está directamente enfrentado a través de esta lectura de Lucrecio. Serres concentra el argumento en el libro II sobre el clinamen tradicionalmente presentado como un absurdo físico. La demostración busca establecer la coherencia y el rigor de la física expuesta en ese poema, quitarle el descrédito 
que el clinamen ha echado sobre el atomismo antiguo. Se apoya en un modelo formal -el de la mecánica de fluidos- desprendido a partir de las metáforas favoritas de Lucrecio. Ese modelo Serres lo toma prestado evidentemente de la física de su época: el estudio de las escorrentías en los medios fluidos que desarrollan Étienne Guyon y Pierre-Gilles de Gennes en la Escuela de Física y Química Industrial, a dos pasos de la Sorbona donde él enseña. Pero Serres no quiere "sancionar" la historia del pasado con la ayuda del presente igual que los bachelardianos. La lluvia de átomos evoca las turbulencias del derrame del montón de arena, pero también el Arenario de Arquímedes. "Aplicando finamente a Epicuro sobre Arquímedes", Serres no sugiere una influencia ni siquiera una verdadera conexión histórica. Piensa simplemente probar la plausibilidad de su interpretación, más que establecer la verdad sobre ese texto, verdad que permanece (de todas maneras) inaccesible al lector moderno. Su práctica de historiador vecina de la hermenéutica, manifiesta una primera exigencia: dar sentido a un texto del pasado. Su puesta en funcionamiento con el texto de Lucrecio transmite una lección: desconfiad de las revoluciones que hacen creer que el pasado ha sido superado. Si lanza una duda sobre los cortes históricos, no por ello Serres entra en el debate de escuela que opone el continuismo al discontinuismo. Escoge otra vía siguiendo sus metáforas. Comte pensó la historia de las ciencias en términos de estados, de estática; la sucesión de los tres estados teológico, metafísico y positivo, imita la de los tres estados de la materia, gaseoso, líquido y sólido. Serres prefiere la metáfora dinámica del flujo del saber, largo río que serpentea y a veces se bifurca a medida que transcurren los accidentes, un flujo lento y viscoso que a veces produce cortes.

Para salir del esquema positivista donde la historia de las ciencias se formó y desarrolló, ha sido necesario perturbar la evidencia del segundo pilar de la obra de Comte: la clasificación de las ciencias. "Todo el mundo habla de historia de las ciencias. Como si existiera. Pues no, no sé qué exista. Sé de monografías o asociaciones de monografías con intersecciones vacías", escribe Serres al comienzo de Punto, plano (red), nube. Esta fórmula provocadora a pedir de boca, interpela a una comunidad de historiadores de las ciencias que está en vías de profesionalización, camino de adquirir una cierta autonomía en las universidades francesas. Historiadores de las matemáticas, astronomía, física, óptica, de esto y de aquello... ¿Qué hacéis pues? No os dejéis entrampar por recortes disciplinarios. No toméis por adquirido lo que está en cuestión. En lugar de meteros en el molde de las disciplinas académicas, preguntaos más bien cómo es que sucedió, cómo el saber se distribuyó así, repartido en islotes, sectorizado.

Seguro que Serres no ha sido el primero en atacar las clausuras-estanco impuestas por la clasificación positivista. Muchos filósofos de las ciencias se han reído de ello recordando que los avances científicos han desbaratado todas 
las prohibiciones comteanas. iFácil! Pero emprender una historia crítica de la clasificación de las ciencias, era un programa más ambicioso. Serres lo aborda investigando la estructura formal que organiza el saber de una época: el punto fijo en el siglo XVII, el plano o red en el XVIII y finalmente la nube con la termodinámica y la mecánica estadística a fines del siglo XIX. Describir la "morena frontal" que distribuye el saber en una época, debe ser el objeto mismo de la historia de las ciencias. La analogía con la episteme de Foucault es bastante sorprendente, pero a las metáforas arqueológicas de zócalo, capa o trazas, Serres prefiere las metáforas geológicas: morenas de glaciares, placas continentales. El derrame del saber presenta masa en movimiento lento que se percibe como fija, inmovilizada. En Serres el estructuralismo hizo una promesa de superar la epistemología regional, la historia compartimentada y el vehículo de una segunda exigencia: salir de lo local para abrazar lo global, esbozar un paisaje enciclopédico.

¿Fue a causa de su tono provocador que este texto de Serres sobre la necesidad de un estudio crítico de las clasificaciones suscitó la ira de Canguilhem? El caso es que en lugar de tratar de responder a ese desafío - como había intentado en 1966 responder al desafío lanzado por Foucault en un postfacio a su libro Lo normal y lo patológico_, en 1977 Canguilhem trata las afirmaciones de Serres condescendientemente. En la introducción a Ideología y racionalidad, presenta a Serres como un joven arrogante, sin duda imbuido de marxismo, que haría bien en leer El racionalismo aplicado de Bachelard antes de disertar sobre la cuestión (Canguilhem, 1990, pp. 18-19).

Remitiendo a Serres al "racionalismo integrador" de Bachelard, Canguilhem no quiso ver que el paso de lo local a lo global exigido por Serres, rebasa los límites de la ciudad de las ciencias. Traduce de hecho una duda más fundamental sobre la posibilidad de trazar una línea de demarcación entre el dominio de la ciencia y el de la no-ciencia, o la pseudo-ciencia. La cultura es un espacio de libre circulación donde Serres viaja y se pasea denegando sus fronteras.

\section{Las matemáticas como tepreno}

En los años setenta, Serres sigue de cerca la ciencia que se está haciendo. A la escucha de Jacques Monod, de François Jacob y de Ilya Prigogine, enriquece y voltea su reflexión hacia la termodinámica y las ciencias del viviente. Pero las matemáticas fueron el terreno donde él se entrenó en el ejercicio filosófico y el aguijón que siempre lo empujó más lejos.

Con el transcurrir de los años, las matemáticas siguen siendo su punto fijo, más bien un signo de interrogación, un tema de perplejidad siempre renovada. Serres regresará sobre ellas en 1992. Luego de haber inspirado las primeras dudas sobre la pertinencia y legitimidad de la epistemología en los años sesenta, 
ahora tenemos que las matemáticas ofrecen la ocasión para un análisis crítico de la historia de las ciencias. Los orígenes de la geometría (obra meditada durante más de treinta años), es en realidad un cuestionamiento de las condiciones de posibilidad de la historia de las ciencias. Poco sorprende que les haya chocado tanto a los historiadores de las matemáticas, pues socava las fundaciones de su casa. A los ojos de Serres, la singularidad de las matemáticas reside en su carácter anhistórico. Más exactamente, las matemáticas están en perpetuo movimiento, pero regresan sobre sus orígenes buscando depurar o estabilizar sus fundamentos. Cada invención reconstruye, reescribe la historia, precipita en el olvido una parte del pasado para reactivar allí mismo otra planteada como origen. "La invención hace la historia, qué importan mis ancestros, iellos descenderán de mí!" (Serres, 1996, p. 22). Amo de la historia como de la ciencia, el inventor rehace la ciencia al mismo tiempo que fabrica un pasado y determina el porvenir.

Este trabajo permanente de reestructuración global, de reencargarse de la totalidad, pone en juego ciertamente la identidad de las matemáticas, pero lanza igualmente al filósofo historiador al más grande apuro. ¿Qué escoger como origen, por dónde comenzar? Los orígenes de la geometría son múltiples y siempre revisitados, en ocasiones precipitados al olvido. Bien ingenuos los filósofos que creen posible asignar un sentido a la historia. Se precisa estar ciego a los múltiples sentidos posibles, al caos de historias para llegar a singularizar un proceso al que se lo naturaliza planteándolo como necesario.

Resumamos: Serres ha hecho una crítica rigurosa a la tradición de filosofía de las ciencias de la que ha heredado. Denunció de manera frecuentemente polémica algunas trampas tendidas por la tradición salida del positivismo: la clasificación de las ciencias, la flecha del progreso y la demarcación entre la ciencia y el resto. Al hacer esto Serres prosigue esta tradición que no termina de denunciar el positivismo de la generación precedente, reactivando a veces ideas más antiguas ${ }^{4}$. La crítica realizada por Serres está impregnada de una idea bien anclada en esta tradición epistemológica: que la ciencia es autónoma, autofundada. Por esto Serres ha podido tomar de las ciencias recursos conceptuales para romper con esta tradición y elaborar su propio concepto de temporalidad. Las matemáticas ofrecen herramientas para sustituir el espacio vectorial de la flecha del tiempo por un espacio topológico con variedades de tiempo fibrado, hojaldrado, etc., y la física de los movimientos lentos de percolación que produce efectos de umbral.

4 Por ejemplo, cuando Serres se agarra con el cientificismo inherente a la epistemología, y la acusa de ser la vitrina publicitaria de la ciencia, es injusto con algunos de los más ilustres representantes de esa tradición epistemológica. Meyerson, por ejemplo, fue uno de los primeros en sostener, mucho antes de Serres, que "encontrará razón, y de la buena, en muchos otros dominios distintos del de la ciencia canónica" (Aclaraciones, p. 94). 


\section{La historia como relato}

Después de haber tomado prestado de las matemáticas y la física herramientas conceptuales, Serres encuentra recursos mucho más ricos en los mitos y relatos. Abandona las ambiciones formalistas para volverse un acontista.

Con un arte consumado, Serres cuenta una historia en cada clase: Tales al pie de las pirámides, la vestal aplastada, el décollage del Challenger, Baal... El inagotable repertorio revela la amplitud de su cultura. Cada relato se presta a múltiples entradas. Cada historia está contada, luego vuelta a contar de otra manera para liberar otras facetas, otras capas de significación. Serres no utiliza el relato para poner punto como se dice por anglicismo, sino que como un pintor puntillista con toquecitos por medio de viñetas sin cesar trabajadas de nuevo, permite ver todo lo que implica el conocimiento. Renunciando al estilo argumentativo en aras de la narración, Serres recita la historia de las ciencias, "fabula" en el sentido estricto, pone la filosofía de las ciencias en fábulas. Pues a mis ojos, Serres nunca ha dejado de gravitar en torno a las ciencias, a pesar de la variedad de los paisajes que visita con su pluma. Permanece en la tradición de historia conceptual, aunque continúa practicando la ojeada histórica, Serres se libera de los constreñimientos de la crítica de los predecesores gracias al poder de la narración. El relato pone de relieve la parte de mito que habita al ideal científico de purificación, de descontaminación, de corte epistemológico.

Por la fuerza del relato y de los mitos, Serres ha logrado que evolucione la epistemología hacia una antropología de las ciencias. En Los orígenes de la geometría anuda juntos los orígenes de la razón (logos o proporción) con la justicia social distributiva. En cuanto a la conexión entre la razón científica y la muerte, que Serres presentaba como un hecho histórico en La thanatocracia" ${ }^{\text {, se vuelve }}$ en "Roma y en Estatuas" un gran mito, un relato portador de sentido para el hombre. La ciencia es un sistema de dos focos: la razón fuente de luz, la única que percibe la mayoría de los filósofos, y la muerte, foco oscuro, fuente siempre oculta, hundida. Así se esboza a través de mitos y relatos, una nueva teoría del conocimiento. Toda luz de conocimiento se paga al precio de una ocultación, el gesto de explicación se duplica en una implicación (Serres y Latour, 2010, p. 107). El conocimiento racional tiene un precio que la epistemología no conoce y que solo una antropología puede revelar. La historia es utilizada aquí como instrumento para desestabilizar la pareja naturaleza/cultura al mismo tiempo que se la historiza.

La antropología de las ciencias (ese término introducido en Estatuas) se justifica de muchas maneras. Para comenzar, el conocimiento científico dibuja

La traducción de este texto se puede consultar en el número 2 de Ciencias Sociales y Educación (2012). Nota del traductor. 
una relación del hombre con el mundo; presupone una separación entre sujeto y objeto. La ciencia moderna ha reducido las cosas o causas a objetos que yacen bajo la mirada de los científicos, y los ha hecho disponibles para ejercer la voluntad de potencia o de posesión de los colectivos humanos. Esta repartición ha sido redoblada, casi naturalizada por la partición entre ciencias de la naturaleza (que hablan del mundo evitando al hombre), y ciencias humanas (que hablan del hombre haciendo abstracción del mundo). Finalmente, la ciencia misma se vuelve un objeto de estudio antropológico en la medida en que ella nutre el mito de una ciencia pura de todo mito.

\section{Herencias}

En su movimiento de la epistemología hacia la antropología, Serres cita a menudo a Georges Dumézil, sobre todo a René Girard ${ }^{6}$. Se reconoce ahora como heredero de una tradición francesa que no tiene ya nada que ver con la de los filósofos e historiadores de las ciencias.

Los y las que han tenido la suerte de seguir sus cursos son a su vez herederos.

A manera de testimonio, diría que Serres fue el que nos liberó del collar de la vulgata bachelardiana. En un tiempo en que los cursos de historia y filosofía de las ciencias recitaban la epistemología de la ruptura, y donde los únicos debates se producían entre los partidarios del continuismo y el discontinuismo, los cursos de Serres abrían un espacio de libertad. Sus críticas con respecto a los guardianes del templo que sacralizan la ciencia aislándola del continente con el cual tiene atadura, autorizaban otra mirada sobre la racionalidad de las ciencias ${ }^{7}$. En particular, la exquisita aproximación de los obstáculos epistemológicos que Bachelard enumera en La formación del espíritu científico con los pecados capitales, mostraba la dimensión moral y religiosa de los imperativos de pureza del discurso científico (Serres, 1981, pp. 105-117). El tono polémico de Bachelard y la amplitud misma de su trabajo de descalificación de los saberes que no eran científicos (que Serres acerca a la cólera, el pecado capital integrado al espíritu científico), revelaba a la vez la violencia inherente a la filosofía del no, y la potencia de esos saberes distintos que se necesitaba erradicar a todo precio.

Como lo ha subrayado Isabelle Stengers y Philipe Pignarre (2005, pp. 22-23, 136), heredar crea obligaciones en el doble sentido del término: el heredero se encuentra en posición de deudor y al mismo tiempo comprometido a hacer algo con lo bien recibido en herencia. La herencia impone un deber de adelantarse.

6 A Girard se le agradece, precisamente ante la comunidad de los historiadores, a comienzos de Roma.

7 Esa otra mirada, fue preciso apuntalarla en la lectura de otros filósofos de la ciencia que la moda bachelardiana entonces dominante había ocultado y echado al olvido: Pierre Duhem, Émile Meyerson, dos blancos favoritos de las críticas de Bachelard, eran indispensables para entender verdaderamente lo que significa la idea entrevista en los cursos de Serres del "precio" de la racionalidad. 
La epistemología de la ruptura ha logrado la proeza de despojar a la opinión (a la antigua doxa, a la que Sócrates y Aristóteles le reconocían un valor político) de todos sus caracteres positivos, para asimilarla a una ignorancia que se ignora ella misma. Si "la opinión piensa mal; (si) no piensa" (Bachelard, 1981, p. 16) ¿Estaríamos la mayoría de nosotros privados de pensamiento? Serres ha suscitado una pregunta que obliga a no separar las cuestiones epistemológicas de los asuntos políticos. ¿Con qué rima una epistemología que descalifica toda forma de pensamiento, desde que él no tenga que ver con los cánones de la ciencia pura? ¿Será algo distinta a una empresa que busca reducir al silencio toda discusión contra expertos y tecnócratas que utilizan la ciencia como una forma de autoridad social? En un periodo en que la conducta de los expertos en los asuntos de la sangre contaminada y de los accidentes como Chernóbil comenzaba a darle peso a las tímidas oposiciones a la nuclear, el cuestionamiento de Serres sobre la autoridad de la ciencia abría una vía de investigación y de acción. ¿Cómo, dónde y en qué circunstancias esta figura de la ciencia como autoridad fue elaborada, difundida, aceptada? Fue con el fin de ver cómo el "espíritu científico", único objeto de atención de los epistemólogos, presuponía una figura de la opinión que emprendía cavar las relaciones históricas entre la ciencia y la opinión (BensaudeVincent, 2000). La representación que las comunidades científicas se hacen de la "otra parte" de la ciencia determina la manera como construyen las ciencias. El estudio histórico de las ciencias debe pues ser completado por una historia de los saberes rechazados. Los excluidos - los charlatanes, aficionados, "pseudocientíficos", vulgarizadores, soñadores, visionarios...- nos enseñan otro tanto que los científicos sobre la construcción de los enunciados científicos. Pero si la epistemología convoca una doxología, si la ciencia tiene necesidad de eso que está en otra parte para fundarse, entonces no se puede seguir diciendo que ella está auto fundada, autorregulada. Su autonomía aparece como un mito.

A decir verdad, en los años ochenta las visiones de Serres se volvían tanto más plausibles y pertinentes cuanto que entraban en resonancia con lo que se hacía en latitudes distintas de la Sorbona. La historia cultural de las ciencias y los science studies que habían conquistado Inglaterra y los Estados Unidos, comenzaban a suplantar en Francia la vieja historia de los conceptos y doctrinas. A fuerza de estudios de caso, de análisis locales y minuciosos, ellos demostraban que las actividades científicas son de parte a parte sociales y ancladas en una cultura. Pero arrancar la ciencia en el aislamiento en que la había confinado la epistemología del siglo XX es algo que exige más que la historia social y cultural de las ciencias. La herencia de Serres obliga a no contentarse con decir que las ciencias son construcciones sociales. Conduce a cuestionar simétricamente la construcción científica de las sociedades contemporáneas, el papel prestado a la ciencia en la administración, la gestión de poblaciones y de migraciones en la vida política. 
Frente a la tentación siempre seductora de reanimar los viejos mitos de la ciencia pura o de la ciencia neutra, ni buena ni mala, ¿puede uno contentarse con relatos? Serres ha tomado sus distancias con respecto a la epistemología cuando percibió que ella era un tanto vana pues constituía una reflexión en espejo, muy pronto interiorizada por los científicos mismos en su esfuerzo por resolver sus crisis. Ahora bien, los científicos de hoy han interiorizado también los relatos. Estamos lejos de la época en que el positivismo imponía votos de castidad y pureza, obligando a las lenguas científicas a abstenerse de imágenes, de visiones y especulaciones. Los grandes relatos sobre el origen del universo, de la vida, la evolución de la humanidad, antaño reservados a los escritores de ciencia popular, a los Figuier, Flammarion, Rostand y Reeves, son en la actualidad ampliamente explotados por investigadores. "Caminar en la luna", "penetrar el secreto de la vida", "hacer el mundo átomo por átomo"... Los objetivos proclamados de los grandes programas científicos muestran hasta qué punto la ciencia tiene necesidad de grandes relatos y la potencia de los mitos para movilizar los recursos — humanos y financieros-, necesarios para el avance siempre arduo de los conocimientos.

¿Cuál es entonces el papel de los filósofos de las ciencias? Se les pide hoy hacer ética. Frente a la amplitud de los cambios ocasionados en nuestra vida cotidiana por los avances de las biotecnologías y las tecnologías de la información, filósofos e historiadores están convocados a participar en la instauración de normas y reglamentaciones para limitar los perjuicios. Fábulas y relatos pueden ciertamente ayudar a responder a esta demanda en la medida en que tienen como vocación escenificar un problema moral, y a veces indicar una línea de conducta.

Sin embargo, si se considera que en vez de predicar la moral nos deberíamos dedicar a elucidar los valores e implicaciones ocultas en la ciencia, se tiene necesita más que nunca de estudios profundos de campo. Por ejemplo, no se puede confiar en un simple vistazo que lea la historia olvidando todos los detalles circunstanciales para desestimar el mito del inventor solitario y genial. ¿Cómo se fabricarían los héroes de la ciencia? ¿Cómo Galileo, Pasteur, Faraday, Darwin, Einstein, se han vuelto símbolos portadores de una visión de la ciencia y de la humanidad? ¿Qué es lo que ese culto de los héroes disimula o busca hacer olvidar? Entendámonos. No se trata de que el filósofo y el historiador se coloquen por encima de la ciencia, y mucho menos sobre las espaldas de los científicos para espiarlos o sospechar de ellos. El análisis fino de los relatos y mitos de los actores de la investigación, muestra una extrema diversidad en la manera como se representan su tema de pesquisa, su propia actividad, su sentido y sus finalidades. Es trabajando concertadamente con los actores de la investigación, sensibilizándolos a las implicaciones de los relatos que ellos o ellas forjan como se puede esperar regular el curso de las ciencias y las técnicas. 
Finalmente, luego de dos decenios la antropología de las ciencias se ha desarrollado considerablemente hasta el punto que las visiones vanguardistas de Serres casi se han vuelto triviales. Como buen heredero, Bruno Latour ha sacado partido en Políticas de la naturaleza (Latour, 2003) de los libros en los que Serres desestabilizaba historizando la pareja naturaleza/cultura. No obstante, Serres y Latour fundamentan el proceso de la idea "moderna" de naturaleza en algunas viñetas históricas (Galileo ante la Inquisición, o el enfrentamiento entre Calicles y Sócrates en el Gorgias) que funcionan como arquetipos o modelos. Ahora bien, este tratamiento de la historia que no tiene nada de historiador, simplifica la cuestión. La dicotomía entre naturaleza y cultura que los antropólogos han historizado y relativizado, precisamente no es sino una cara del problema. Pues esta idea de naturaleza objetiva sometida a la mirada dominadora o posesiva de los humanos no procede de una sola dicotomía. Pone en juego un tercer término que nos entregaron los antiguos griegos. Si las controversias con los sofistas han puesto en primer plano la separación entre physis, la naturaleza y nomos, la convención, el dominio de lo político, las controversias sobre el estatuto de los artesanos y la legitimidad del arte médico han opuesto la physis y los technai, los productos del arte humano (Bensaude-Vincent, William y Newmann, 2007). Ahora bien, la dicotomía entre naturaleza y artificio —en la actualidad constantemente movilizada en los debates éticos sobre las nuevas tecnologíasno se puede superponer a la dicotomía naturaleza y cultura. En la historia de la ciencia occidental, la segunda ha funcionado completamente al revés de la primera. La distinción naturaleza/sociedad pone al hombre en el centro y a la naturaleza en la periferia, como Serres lo ha subrayado en el Contrato natural. A la inversa, la distinción aristotélica entre naturaleza y artificio ha sido blandida por los escolásticos para limitar los derechos y privilegios humanos (el arte, imitación de la naturaleza, no es más que una falsificación), para volver a colocar al hombre en su sitio en la creación. La repartición naturaleza/sociedad se opone a un pensamiento mágico o religioso que delimita un espacio sometido a las leyes y un espacio que tiene que ver con la arbitrariedad humana. En contraposición, la distinción naturaleza/artificio fue históricamente el escudo de un pensamiento religioso que condenaba la técnica como tentativa para igualar a Dios, y rivalizar con el Creador. En resumen, si la distinción naturaleza/sociedad condiciona la modernidad, la distinción naturaleza/técnica es generalmente reconocida como un obstáculo para la modernidad. Es necesario precisamente expulsar esa distinción para considerar al hombre como amo y poseedor de la naturaleza. Descartes borra la distinción entre lo natural y lo artificial ${ }^{8}$, pero cava la diferencia entre el sujeto y el objeto, transformando la naturaleza en objeto disponible por el sujeto que no hace parte de ella.

Descartes (1995) afirma en Los Principios de la filosofía, IV parte, § 203: "No reconozco ninguna diferencia entre las máquinas que hacen los artesanos y los diversos cuerpos que la naturaleza compone sola". 
De este modo, la herencia de Serres obliga a un tratamiento menos desenvuelto de la historia, a no verla como un patrimonio cultural del cual se puede libremente extraer recursos para ponerlos a disposición, sino más bien como una limitación que nos obliga a reformular sin cesar los problemas.

\section{Referencias}

Bachelard, G. (1981). La formación del espíritu científico. México: Siglo XXI.

Bensaude-Vincent, B. (2000). L'Opinion publique et la science. À chacun son ignorance. París: Synthélabo.

Bensaude-Vincent, B., William R. y Newmann. (2007). The Artificial and the Natural. An evolving Polarity. Cambridge: MIT Press.

Bergson, H. (1915). La Philosophie. En L. Poincaré, La Science française à l'exposition de San Francisco (vol. 1). París: Ministerio de la instrucción pública.

Boutroux, É. (1911). Du rapport de la philosophie aux sciences, Scientia, 9(18).

Brenner A. (2003). Les origines françaises de la philosophie des sciences. París: PUF.

Canguilhem G. (1990). El papel de la epistemología en la historiografía científica contemporánea. En G. Canguilhem. Ideología y racionalidad en la historia de las ciencias de la vida (Luis Alfonso Paláu y María Gómez, trad.). Medellín: Universidad Nacional de Colombia.

Canguilhem, G. (1992a, julio). "La filosofía biológica de Augusto Comte y su influencia en la Francia del siglo XIX". En G. Canguilhem. Estudios de historia y de filosofía de las ciencias (María Luisa Jaramillo, María Cecilia Gómez y Luis Alfonso Paláu, trad.) Seminario de Historia de la Biología. Universidad Nacional de Colombia, sede Medellín.

Canguilhem, G. (1992b, julio). "El objeto de la historia de las ciencias". En G. Canguilhem. Estudios de historia y de filosofía de las ciencias (Ma. L. Jaramillo, Ma. C. Gómez y L. A. Paláu, trad.) Seminario de Historia de la Biología. Universidad Nacional de Colombia, sede Medellín.

Comte A. (1975). Cours de philosophie positive (vol. 2). París: Hermann.

Descarte, R. (1995). Los Principios de la filosofía. Madrid: Alianza.

Latour, B. (2003). Politique de la nature. París: la Découverte.

Pignarre, P. y Stengers I. (2005). La Sorcellerie capitaliste. París: La decouverte.

Serres, M. (1996). Los orígenes de la geometría. Tercer libro de las fundaciones. México: Siglo XXI.

Serres, M. (1998). Rome: Le livre des foundations. París: Grasset, 1983 (Luis Alfonso Paláu, trad.). Medellín, Posgrado de Estética. Universidad Nacional de Colombia.

Serres, M. (2012). Traición: la thanatocracia, Ciencias Sociales y Educación, 2(1), pp. 189-215.

Serres, M. (2010). Aclaraciones (Luis Alfonso Paláu). Medellín.

Michel Serres. "Deontología: la Reforma y los siete pecados" in Hermes II: la Interferencia. Tr. por L. A. Paláu (Medellín, Año Sabático 1996. pp. 105-117). Buenos Aires: Almagesto. 